\title{
Some characteristics of repeated sickness absence
}

\author{
DAVID FERGUSON \\ Occupational Health Section, School of Public Health and Tropical Medicine, \\ University of Sydney, Australia
}

Ferguson, D. (1972). Brit. J. industr. Med., 29, 420-431. Some characteristics of repeated sickness absence. Several studies have shown that frequency of absence attributed to sickness is not distributed randomly but tends to follow the negative binomial distribution, and this has been taken to support the concept of 'proneness' to such absence. Thus, the distribution of sickness absence resembles that of minor injury at work demonstrated over 50 years ago. Because the investigation of proneness to absence does not appear to have been reported by others in Australia, the opportunity was taken, during a wider study of health among telegraphists in a large communications undertaking, to analyse some characteristics of repeated sickness absence.

The records of medically certified and uncertified sickness absence of all 769 telegraphists continuously employed in all State capitals over a two-and-a-half-year period were compared with those of 411 clerks and $\mathbf{4 1 5}$ mechanics and, in Sydney, 380 mail sorters and 80 of their supervisors. All telegraphists in Sydney, Melbourne, and Brisbane, and all mail sorters in Sydney, who were available and willing were later medically examined. From their absence pattern repeaters (employees who had had eight or more certified absences in two and a half years) were separated into three types based on a presumptive origin in chance, recurrent disease and symptomatic non-specific disorder.

The observed distribution of individual frequency of certified absence over the full two-and-ahalf-year period of study followed that expected from the univariate negative binomial, using maximum likelihood estimators, rather than the Poisson distribution, in three of the four occupational groups in Sydney. Limited correlational and bivariate analysis supported the interpretation of proneness ascribed to the univariate fit. In the two groups studied, frequency of uncertified absence could not be fitted by the negative binomial, although the numbers of such absences in individuals in successive years were relatively highly correlated.

All types of repeater were commoner in Sydney than in the other capital city offices, which differed little from each other. Repeaters were more common among those whose absence was attributed to neurosis, alimentary and upper respiratory tract disorder, and injury. Out of more than 90 health, personal, social, and industrial attributes determined at examination, only two (ethanol habit and adverse attitude to pay) showed any statistically significant association when telegraphist repeaters in Sydney were compared with employees who were rarely absent. Though repeating tended to be associated with chronic or recurrent ill health revealed at examination, one quarter of repeaters had little such ill health and one quarter of rarely absent employees had much.

It was concluded that, in the population studied, the fitting of the negative binomial to frequency of certified sickness absence could, in the circumstances of the study, reasonably be given an interpretation of proneness. In that population also repeating varies geographically and occupationally, and is poorly associated with disease and other attributes 
uncovered at examination, with the exception of the ethanol habit. Repeaters are more often neurotic than employees who are rarely absent but also are more often stable double jobbers.

The repeater should be identified for what help may be given him, if needed, otherwise it would seem more profitable to attack those features in work design and organization which influence motivation to come to work. Social factors which predispose to repeated absence are less amenable to modification.

Individual and group differences in absence attributed to sickness need not be the result of differences in disease incidence (see for example, Gafafer, 1943; Plummer and Hinkle, 1955; Blumberg and Coffin, 1956; Chiesman, 1957; Shepherd and Walker, 1958; Schilling, 1960; and Taylor, 1968a). Such absence is usually the resultant of several factors, only one or none of which may be medical. Blumberg and Coffin (1956) listed many non-medical personal, social, industrial, and organizational factors and considered that almost any personnel practice may influence absenteeism by affecting desire to work. Acheson (1968) identified also medical practice and hospital factors.

The numbers of absences incurred by individuals in any one period are not distributed randomly but tend to follow the negative binomial distribution. Greenwood (Greenwood and Woods, 1919; Greenwood and Yule, 1920) first chose the binomial (Pearson type III) curve to represent the distribution of the unequal liabilities to accident of 14 groups of female munitions workers. The univariate distribution has been applied to frequencies of certified sickness absence by Russell, Whitwell, and Ryle (1947), Sutherland and Whitwell (1948), Hinkle, Pinsky, Bross, and Plummer (1956), Taylor (1967), and Ferguson (1969). Russell et al. assumed that the distribution applied also to uncertified absence. Arbous and Sichel (1954) fitted the distribution to 'absences which occur (for various reasons) to individuals', and Sichel (1951) to absences classed as 'absent without permission' in the same population. Glasser (1970) incorporated a seasonal factor in similarly characterizing 'illness absenteeism' without specifying type oi absence. Froggatt (1970b) alone has studied short-term absence in this way. The distribution has also been successfully fitted to analyses of individual frequencies of consultations in general practice (Froggatt, Dudgeon, and Merrett, 1969).

Russell et al. (1947) considered the fitting of Greenwood and Yule's (1920) model to certified illness as evidence of 'sickness-proneness' due either to chronic or recurring physical disabilities or to social irresponsibility, a term mentioned by Bashford (1942) in referring to 'a too light-hearted taking of a day or two off for medical or semi-medical reasons'. The semantic and other problems inherent in the term 'accident proneness' apply also to such terms, derived from it, as absence, illness or sickness proneness. Farmer and Chambers (1926) introduced 'accident prone' in the sense of prone as having a natural tendency (Shorter Oxford English Dictionary) or personal idiosyncrasy, as distinct from accident liability in the sense of liability as being exposed to or likely to suffer from (something prejudicial), which includes all factors determining accident rate. If environmental exposure were the same for all in a group, liability should measure proneness, assuming that the overt consequence of liability being measured (whether absence, injury or consultation) is closely related thereto (Froggatt et al., 1969). Terms such as accident or absence 'repeating', being merely descriptive, avoid the inflexible connotation of proneness (Froggatt and Smiley, 1964). The pejorative 'absence offender' (Arbous and Sichel, 1954) and 'unjustified repeater' (Fortuin, 1955) reveal attitudes to absence, though the former authors deemed absenteeism symptomatic of occupational casualty. The 'thick file' or 'familiar face' syndrome (Kemp, 1963), that is, liability to attend in general or hospital practice, is an equivalent of liability to be absent.

The heterogeneous nature of liability to accident or absence in any industrial population occurs irrespective of occupation (Taylor, 1967), though the form of the curve varies with age and occupational subgroup (Glasser, 1970). Liability is postulated to be relatively invariant in any one individual in a stable environment but need only represent the nett effect of many factors, not each constant for the individual but having an overall constant effect. Further, the effects of personal and environmental influences cannot readily be dichotomized and interactions occur. The components of liability are unidentifiable, liability can be only poorly estimated, and characteristics of the prone individual are difficult to establish (Froggatt et al., 1969).

Many workers have pointed out that proneness is not estimated sufficiently by fitting the univariate negative binomial to observations, that this distribution may be generated by different, possibly opposing assumptions (Arbous and Sichel, 1954), and that other possibilities have not yet been exhausted (Bliss and Fisher, 1953). Froggatt (1970b) discussed four possible confounding factors in the interpretation of the satisfactory fit of his short-term absence data by the negative binomial distribution. 
These included unequal 'exposure to risk', bias (e.g., tendency to report rather than to have), clustering of episodes, and 'contagion' in the sense that the occurrence of absence may change the likelihood of further absence. Froggatt et al. (1969) discussed similar confounding of attendance in general practice. A person with symptoms may or may not seek diagnosis, accept treatment or be absent from work (Semmence, 1971), and the doctor's advice will vary similarly.

Arbous and Sichel (1954) traced recognition of the inadequacy of inferences drawn from fitting of theoretical univariate distributions to sets of observations and concluded that the existence of proneness in absence behaviour could be established only by correlation. Interperiod correlations for certified sickness absence have been noted by Lokander (1962) and Taylor (1968a), though the coefficients tend to fall as the interval between periods increases for short-term absence (Froggatt, $1970 \mathrm{~b}$ ), presumably due to unequal environmental change even when liability is unchanged. Bivariate analysis, using the correlation coefficient derived from the two parameters of the negative binomial for a single period (Arbous and Sichel, 1954) to extend the interpretation, has been applied by Froggatt (1970a) to short-term absence, and by Froggatt et al. (1969) to consultations in general practice.

Various authors have compared the characteristics of the repeated absentee and his opposite, called the 'presentee' by Smith (1970). Taylor (1968b) noted that the 'never sick' in his population differed from the frequently sick in that they were often shiftworkers, punctual, physically active, stable, introverted, and satisfied with their job. However, Hinkle, Plummer, and Whitney (1961) noted that frequent absence was not necessarily associated with undesirable qualities.

Analysis of unequal likelihood of absence attributed to sickness does not appear to have been reported previously in Australia. In the course, therefore, of a wider study (Ferguson, 1969) of health among telegraphists in a large public undertaking, the opportunity was taken to define some characteristics of the repeated taking of such absence. Unless otherwise stated 'sickness absence' means absence from work attributed to sickness on a medical certificate. The term 'significant' is used only in the statistical sense $(P<0.05)$, and the term 'associated' only when the connection referred to was significant.

\section{Material and method}

All employees in the organization studied are allowed 10 working days sick leave a year on full pay and 10 days on half pay, provided the leave is medically certified. Un- expended certified sick leave can accumulate but is not credited at the end of service. The four days of sick leave allowed each year without certificate are mostly (94\%) taken singly; the other $6 \%$ comprise two-day absences.

The sickness absence records of all 769 telegraphists continuously employed in all capital city head offices of the undertaking over a two-and-a-half-year period were compared with those of 411 clerks and 415 mechanics taken as every $n$th employee from alphabetical lists. Because total sickness absence was much greater in Sydney telegraphists than in those of any other capital, which differed little among themselves, the 472 records in the other capitals were combined for comparison with the 297 in Sydney. For the same reason, the records of 380 mail sorters and 80 supervisors in Sydney were added. The weekly-change shift conditions, work, and pay of mail sorters more closely resembled those of telegraphists than any other group in the undertaking; employees in either group could arrange with others to exchange shifts. Clerks and mechanics were day workers from Monday to Friday. Because of selective factors in the choice of shifts, the study could not constitute a comparison of the effects of shift and day work on repeaied absence.

Allowances were made for differences in age distribution between occupational groups. All groups studied were male.

Classes were selected for main disease groups (Ferguson, 1969) based on the method of the London Transport Executive (1956) and using the code numbers of the International Classification of Diseases (World Health Organization, 1957). Working days lost were transformed to calendar days lost by reference to calendars of the period. Episodes which started before and extended into the period surveyed, or which continued beyond the end, were not included on the absence records.

All telegraphists in Sydney, Melbourne, and Brisbane, and all mail sorters in Sydney, who were available and willing were subsequently given a comprehensive medical interview and examination without the examiner knowing, at the time, the absence records of the individuals concerned (Ferguson, 1971).

The overall and age rates of sickness absence in the four occupational groups studied are reported elsewhere (Ferguson, 1969). In general, Sydney telegraphists and mail sorters had a great excess of one- to five-day absences compared with clerks and mechanics, whose rates were similar. Telegraphists had many more longer absences than did mail sorters.

\section{Types of repeaters}

A repeater was defined as one who had taken eight or more certified absences in the two-and-a-halfyear period. Repeaters were separated into three types based on Fortuin's classification (1955):

1. 'chance' repeaters - persons with an increased number of absences of varied and causally unrelated nature, presumably as a result of chance;

2. 'recurrent' repeaters - persons certified as suffering from a disease or diseases involving 
recurrent disability, such as bronchial asthma; and

3. 'symptomatic' repeaters - persons whose certified diagnoses of sickness absence were usually vague or symptomatic, or otherwise gave rise to doubt as to the medical reason for the absence.

Some persons with very numerous absences showed features classing them as both chance and recurrent repeaters; in these cases the dominant type was selected. Some who displayed the characteristics of a symptomatic repeater with those of either a chance or recurrent repeater were classed as one of these latter types. Examples of each type of repeater, chosen at random, are shown in Table 1 . A repeater was not classed as recurrent unless he had been absent four or more times in two and a half years with a particular disorder.

The person whose record is shown in Table 1 as an example of a chance repeater was found when examined later to have, at the age of 37 years, a blood pressure of $220 / 110 \mathrm{mmHg}$ and chronic renal and valvular heart disease.

The person exemplifying a recurrent repeater had two diagnoses, ulcer and haemorrhoids, on his sickness record to account for his excess absence, with a third, asthma, not in this case being responsible for repeated absence; at interview none of these diagnoses was made. The main diagnoses in recurrent repeaters are shown in Table 2.

The person judged on his record as a symptomatic repeater (Table 1) was considered at interview to have moderately severe depressive neurosis and nasal allergy; the former diagnosis, together with a broken marriage and a subsequent turbulent de facto relationship, probably explain the frequent vague

\section{T A B L E 1}

Medically Certified Diagnoses in $2 \frac{1}{2}$ Years; Examples OF THREe TyPes OF RePEATER

\begin{tabular}{|c|c|c|}
\hline \multicolumn{3}{|c|}{ Type of repeater } \\
\hline Chance & Recurrent & Symptomatic \\
\hline Fibrositis & Peptic ulcer & $\begin{array}{l}\text { URTI } \\
\text { (6times) }\end{array}$ \\
\hline $\begin{array}{r}\text { Influenza } \\
\text { (twice) }\end{array}$ & $\begin{array}{l}\text { Haemorrhoids } \\
\text { (9 times) }\end{array}$ & $\begin{array}{l}\text { Gastritis } \\
\text { (6 times) }\end{array}$ \\
\hline Finger infection & Asthma & $\begin{array}{l}\text { Gastro-enteritis } \\
\text { (5 times) }\end{array}$ \\
\hline Elbow strain & Pharyngitis & $\begin{array}{l}\text { Neuritis } \\
\text { (thrice) }\end{array}$ \\
\hline Shingles & & Neurosis \\
\hline Ear infection & & Injured thumb \\
\hline Bronchitis & & Fibrositis \\
\hline
\end{tabular}

T A B L E 2

Main Medically Certified Diagnoses in ReCURRENT REPEATERS

\begin{tabular}{|c|c|c|c|c|c|c|}
\hline Neurosis & $\ldots$ & 13 & Other gut & $\ldots$ & . & 5 \\
\hline Fibrositis & . & 8 & Asthma & . . & . & 5 \\
\hline Joint & . $\quad \ldots$ & 7 & Bronchitis & . & . . & 5 \\
\hline Rhinitis, nas & sal allergy & 7 & Dermatoses & & . & 4 \\
\hline Peptic ulcer & . & 6 & Other & . & . & 11 \\
\hline
\end{tabular}

diagnoses, but the ethanol problem suggested by these diagnoses was not revealed at interview. Absence attributed to gastritis was met frequently; the diagnosis was treated as symptomatic rather than recurrent, though no doubt gastritis was indeed present if drinking was responsible for these absences. Covering by mates and supervisors was said to occur extensively, and drinkers' physicians apparently covered in their certificates; $30 \%$ of heavy drinkers (defined below), as against $3 \%$ of other employees, were noted to have had one or more episodes of gastritis in their sickness absence records $\left(\chi^{2}=38.21, \mathrm{P}<0.001\right)$.

\section{Results}

Incidence and distribution of repeated absence

On the criteria described, a total of 172 repeaters $(8.4 \%)$ was identified; they were fairly evenly distributed by age.

All types of repeater were commoner in Sydney than in other capital city offices, which varied little between each other (Table 3). Recurrent and symptomatic repeaters were equally common among

T A B L E 3

Types of Repeater by CAPITAl City Office and BY OCCUPATION IN SYDNEY

\begin{tabular}{|c|c|c|c|c|c|}
\hline \multirow{2}{*}{$\begin{array}{c}\text { By capital } \\
\text { All occupations }\end{array}$} & \multirow{2}{*}{ No. } & \multicolumn{4}{|c|}{ Percentage of repeaters } \\
\hline & & Chance & $\begin{array}{l}\text { Recur- } \\
\text { rent }\end{array}$ & $\begin{array}{c}\text { Sympto- } \\
\text { matic }\end{array}$ & $\begin{array}{c}\text { All } \\
\text { types }\end{array}$ \\
\hline $\begin{array}{l}\text { Sydney } \\
\text { Melbourne } \\
\text { Brisbane } \\
\text { Adelaide } \\
\text { Perth . . }\end{array}$ & $\begin{array}{l}955 \\
389 \\
322 \\
235 \\
146\end{array}$ & $\begin{array}{l}6 \\
1 \\
1 \\
2\end{array}$ & $\begin{array}{l}5 \\
2 \\
2 \\
1 \\
3\end{array}$ & $\begin{array}{l}4 \\
1 \\
0 \cdot 3 \\
1\end{array}$ & $\begin{array}{r}14 \\
4 \\
3 \\
3 \\
3\end{array}$ \\
\hline \begin{tabular}{l}
\multicolumn{1}{c}{$\begin{array}{c}\text { occupation, } \\
\text { Sydney }\end{array}$} \\
Telegraphists \\
Mail sorters \\
Clerks . \\
Mechanics . \\
Mail supervisors
\end{tabular} & $\begin{array}{r}297 \\
380 \\
99 \\
99 \\
80\end{array}$ & $\begin{array}{l}9 \\
6 \\
2 \\
2 \\
2\end{array}$ & $\begin{array}{r}5 \\
6 \\
4 \\
1 \\
10\end{array}$ & $\begin{array}{l}5 \\
5\end{array}$ & $\begin{array}{r}20 \\
16 \\
6 \\
3 \\
12\end{array}$ \\
\hline
\end{tabular}


Sydney telegraphists and mail sorters, but there were more chance repeaters among the former.

No clerk, and only one mechanic, in any State was a symptomatic repeater, and there were no repeaters of any type among clerks in Melbourne, Adelaide or Perth. Of the 472 telegraphists from offices other than Sydney, $24(5 \%)$ were repeaters, and of these $3(0.6 \%)$ were symptomatic. Two $(0.6 \%)$ of the 312 clerks from the combined offices other than Sydney, and 7 (2\%) of the 316 mechanics from these offices, were repeaters. Sydney telegraphists and clerks had far greater proportions of repeaters than had their counterparts in other offices but Sydney mechanics were little in excess. The proportions of repeaters in telegraphists were similar in Melbourne $(6 \%)$, Adelaide $(6 \%)$, and Perth $(7 \%)$ but less in Brisbane ( $2 \%)$.

In practice the separation of repeaters into the three types was not clearly revealed either in the distribution of numbers of certified absences (Fig. 1) or in the distribution of durations of absences (Fig. 2). As expected, chance repeaters mostly only just reached the arbitrary starting point of repeating, eight absences in two and a half years, or exceeded it only by one or two absences, and recurrent repeaters were little more often absent, whereas few symptomatic repeaters had only eight or nine absences. As expected also, durations of one to three days were commonest in symptomatic repeaters. The distribution of durations of absences in repeaters as a whole differed much from that in non-repeaters (Fig. 3); also, the former did not show the usual peak at one-week intervals, shown by the latter. Because of the geographic and occupational differences noted above these comparisons were made in one group only, Sydney telegraphists.

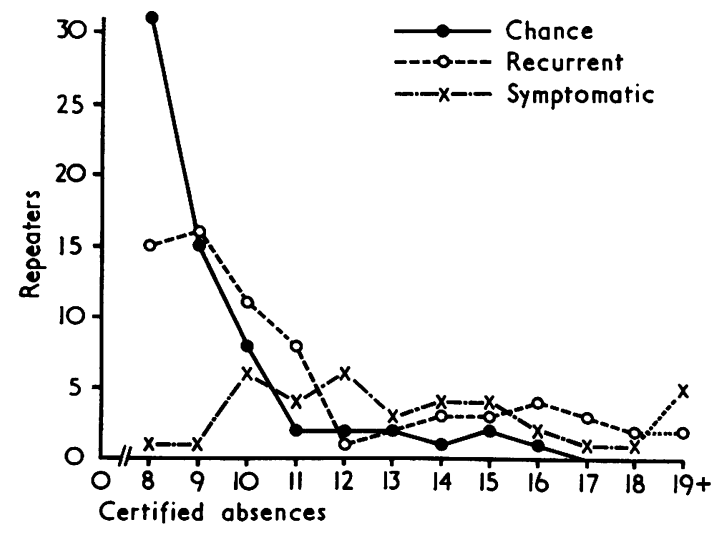

FIG. 1. Distribution of numbers of certified absences by type of repeater.

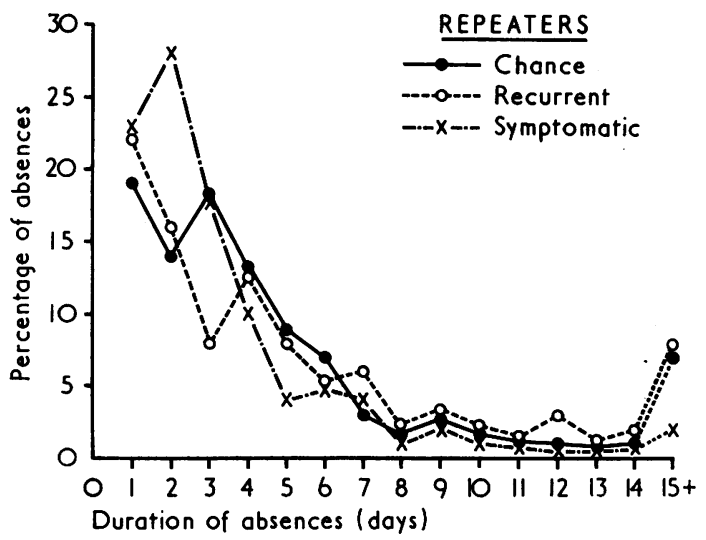

FIG. 2. Distribution of durations of certified absences by type of repeater.

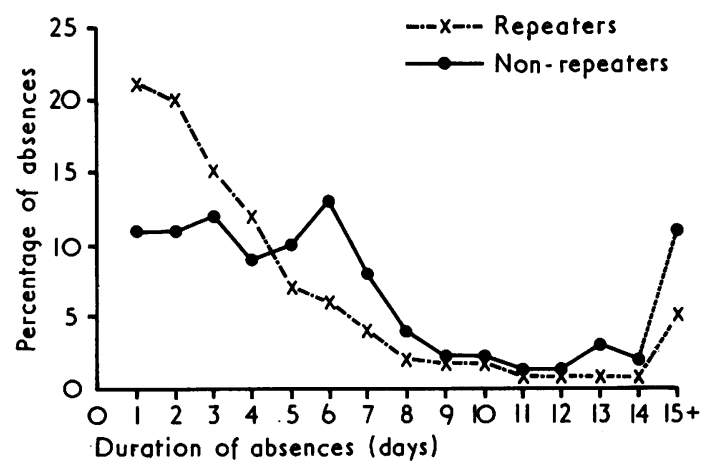

FIG. 3. Comparison of durations of certified absences in repeaters and non-repeaters.

Observed and expected frequencies of sickness absence

The observed distribution of frequency of certified sickness absence in individual employees over the full two-and-a-half-year period of study did not differ significantly from that expected from the univariate negative binomial, derived by maximum likelihood, in three of the four occupational groups in Sydney, whereas it differed widely from the Poisson distribution (Table 4, Fig. $4^{1}$ ).

Correlational and bivariate evidence was sought for the interpretation of proneness hypothesized from the univariate distribution. The observed frequencies of certified absence in two successive 12-month periods in the two and a half years did not depart significantly from those expected in the two largest Sydney groups (Table 5). It was noteworthy that the numbers of mail sorters having no certified

'Fig. 4 demonstrates the exception to the general statement about the closeness of the observed and univariate negative binomial distributions. 
T A B L E 4

Observed and Theoretical Negative Binomial (NB) and Poisson (P) Distributions of Numbers of Certified Sickness Absences per Employee in $2 \frac{1}{2}$ Years among Four OCcupational Groups in Sydney, using Maximum LIKELIHOOD ESTIMATES

\begin{tabular}{|c|c|c|c|c|c|c|c|c|c|c|c|c|}
\hline \multirow{2}{*}{$\begin{array}{c}\text { No. of } \\
\text { absences }\end{array}$} & \multicolumn{3}{|c|}{ Telegraphists (297) } & \multicolumn{3}{|c|}{ Mail sorters $(380)$} & \multicolumn{3}{|c|}{ Clerks (99) } & \multicolumn{3}{|c|}{ Mechanics (99) } \\
\hline & Observed & $N B^{1}$ & $P^{1}$ & Observed & $N B^{2}$ & $P^{2}$ & Observed & $N B^{3}$ & $P^{3}$ & Observed & $N B^{4}$ & $P^{4}$ \\
\hline \multirow[t]{3}{*}{$\begin{array}{l}0 \\
1 \\
2 \\
3 \\
4 \\
5 \\
6 \\
7 \\
8 \\
9+\end{array}$} & $\begin{array}{l}31 \\
46 \\
53 \\
30 \\
27 \\
17 \\
18 \\
13 \\
17 \\
45\end{array}$ & $\begin{array}{l}37 \cdot 6 \\
41 \cdot 7 \\
38 \cdot 8 \\
33 \cdot 8 \\
28 \cdot 4 \\
23 \cdot 4 \\
18 \cdot 9 \\
15 \cdot 2 \\
12 \cdot 1 \\
43 \cdot 3\end{array}$ & $\begin{array}{r}3.4 \\
15 \cdot 2 \\
33 \cdot 8 \\
50 \cdot 2 \\
55 \cdot 9 \\
49 \cdot 8 \\
37 \cdot 0 \\
23 \cdot 5 \\
13 \cdot 1 \\
11 \cdot 2\end{array}$ & $\begin{array}{l}59 \\
60 \\
59 \\
56 \\
30 \\
24 \\
19 \\
12 \\
17 \\
44\end{array}$ & $\begin{array}{l}61 \cdot 1 \\
61 \cdot 7 \\
53 \cdot 8 \\
44 \cdot 5 \\
35 \cdot 8 \\
28 \cdot 4 \\
22 \cdot 2 \\
17 \cdot 2 \\
13 \cdot 2 \\
42 \cdot 0\end{array}$ & $\begin{array}{r}8 \cdot 3 \\
31 \cdot 6 \\
60 \cdot 5 \\
77 \cdot 3 \\
74 \cdot 0 \\
56 \cdot 6 \\
36 \cdot 1 \\
19 \cdot 8 \\
9 \cdot 5 \\
6 \cdot 3\end{array}$ & $\begin{array}{r}16 \\
24 \\
25 \\
14 \\
6 \\
1 \\
6 \\
1 \\
2 \\
4\end{array}$ & $\begin{array}{r}20 \cdot 0 \\
21 \cdot 3 \\
17 \cdot 6 \\
13 \cdot 1 \\
9 \cdot 2 \\
6 \cdot 3 \\
4 \cdot 2 \\
7 \cdot 4 \\
- \\
-\end{array}$ & $\begin{array}{r}7 \cdot 7 \\
19 \cdot 6 \\
25 \cdot 1 \\
214 \\
13 \cdot 7 \\
11 \cdot 5 \\
- \\
- \\
-\end{array}$ & $\begin{array}{r}27 \\
25 \\
14 \\
13 \\
5 \\
7 \\
3 \\
2 \\
1 \\
2\end{array}$ & $\begin{array}{r}27 \cdot 9 \\
22 \cdot 6 \\
16 \cdot 2 \\
11 \cdot 1 \\
7 \cdot 4 \\
4 \cdot 9 \\
3 \cdot 2 \\
5 \cdot 8 \\
- \\
-\end{array}$ & $\begin{array}{c}11 \cdot 6 \\
24.9 \\
26.7 \\
19 \cdot 0 \\
10.2 \\
66 \\
- \\
- \\
-\end{array}$ \\
\hline & $\begin{array}{l}x^{2} \\
\mathrm{df} \\
P\end{array}$ & $\begin{array}{c}27 \cdot 04 \\
15 \\
0 \cdot 02-0 \cdot 05\end{array}$ & $\begin{array}{c}436.6 \\
8 \\
<0.001\end{array}$ & $\begin{array}{l}x^{2} \\
\text { df } \\
P\end{array}$ & $\begin{array}{c}12 \cdot 94 \\
14 \\
0 \cdot 60-0 \cdot 70\end{array}$ & $\begin{array}{c}628.8 \\
8 \\
<0.001\end{array}$ & $\begin{array}{l}x^{2} \\
\mathrm{df} \\
\mathrm{P}\end{array}$ & $\begin{array}{c}10 \cdot 70 \\
5 \\
0 \cdot 05-0 \cdot 10\end{array}$ & $\begin{array}{c}17.34 \\
4 \\
<0.005\end{array}$ & $\begin{array}{l}\chi^{2} \\
\mathrm{df} \\
P\end{array}$ & $\begin{array}{c}2.73 \\
5 \\
0.70-0.80\end{array}$ & $\begin{array}{c}41.72 \\
4 \\
<0.001\end{array}$ \\
\hline & & $\begin{array}{l}\text { Mean } \\
\text { Variance }\end{array}$ & $\begin{array}{c}4.454 \\
19.208 \\
k=1.479\end{array}$ & & $\begin{array}{l}\text { Mean } \\
\text { Variance }\end{array}$ & $\begin{array}{r}3.829 \\
14 \cdot 733 \\
k=1.370\end{array}$ & & $\begin{array}{l}\text { Mean } \\
\text { Variance }\end{array}$ & $\begin{array}{r}2.555 \\
7.555 \\
k=1.832\end{array}$ & & $\begin{array}{l}\text { Mean } \\
\text { Variance }\end{array}$ & $\begin{array}{c}2 \cdot 141 \\
6.061 \\
k==1 \cdot 303\end{array}$ \\
\hline
\end{tabular}

${ }^{1}$ Calculated using up to 17 episodes; seven men had more than 17 episodes, ranging up to 42 in one man ${ }^{2}$ Calculated using up to 16 episodes; four men exceeded 16 episodes

${ }^{3}$ Calculated using up to 7 episodes; only 4 clerks and 2 mechanics had more than 8 episodes

'Calculated using up to 5 episodes

absences decreased greatly in the second year, much more than in telegraphists, which could be ascribed at least in part to the severe Australia-wide epidemic of influenza in that year.

The increased numbers of absences attributed to influenza were noted in all occupational groups studied in all capital cities; the relative increase was

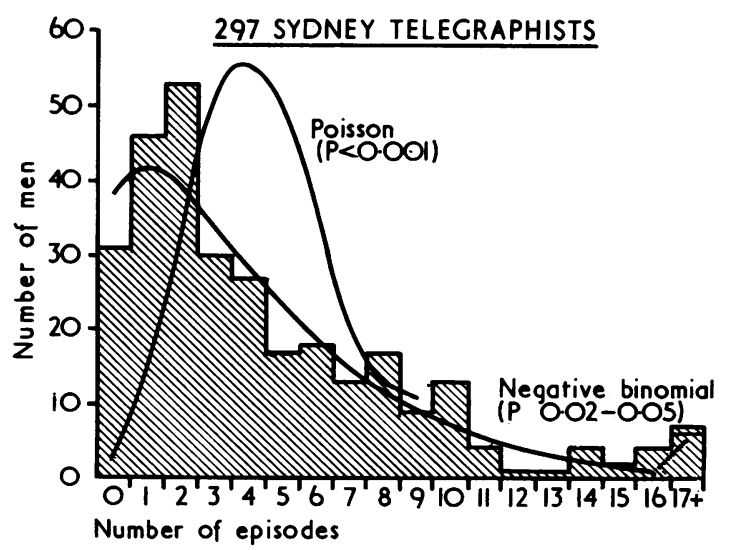

FIG. 4. Actual (histogram) and calculated Poisson and univariate negative binomial distributions of numbers of certified absences in Sydney telegraphists over a twoand-a-half-year period. Parameters of negative binomial estimated by maximum likelihood. less in telegraphists than in mail sorters in Sydney $\left(\chi^{2}=4.48, \mathrm{P}<0.05\right)$ for no clear reason (Table 6).

The observed distribution of uncertified absence in mail sorters departed significantly from that expected, in both years (Table 5); in telegraphists, the distribution departed so widely in either year that it obviously could not be described closely by the negative binomial. Influenza apparently did not have the same effects on uncertified as on certified absence; the numbers of employees having 0 to 1 uncertified absences differed little between the two years. The positive exponential $k$ and its standard error for certified absence were generally stable in telegraphists in the two years when estimated by any of the methods used (Table 7), but less so in mail sorters. The $\chi^{2}$ value was in each case least using maximum likelihood estimators. The parameter was quite unstable in uncertified absence rendering the distribution unsuitable in this case. The observed product-moment correlation between the numbers of certified absences incurred by each individual in the two successive years in the case of telegraphists (Table 8) exceeded the expected co-efficient $(\rho=\mathrm{m} / \mathrm{m}$ $+\mathrm{k}$ ) derived from the parameters of the univariate negative binomial based on the first year's data (Arbous and Sichel, 1954), and in mail sorters was less. The differences when tested by $\mathrm{z}$ transformation were not significant, though such testing has doubtful validity.

The interyear correlation for uncertified absence in 
T A B L E 5

Observed and Expected Negative Binomial Distributions of Certified and Uncertified Sickness Absence in Successive Years in Mail Sorters and of Certified Absence in t flegraphists, in Sydney, using Maximum LikeliHOOD ESTIMATES

\begin{tabular}{|c|c|c|c|c|c|c|c|c|c|c|c|c|c|c|}
\hline \multicolumn{10}{|c|}{ Certified absence } & \multicolumn{5}{|c|}{ Uncertified absence } \\
\hline \multicolumn{5}{|c|}{ Telegraphists } & \multicolumn{5}{|c|}{ Mail Sorters } & \multicolumn{5}{|c|}{ Mail Sorters } \\
\hline \multirow{2}{*}{$\begin{array}{c}\text { No. of } \\
\text { absences }\end{array}$} & \multicolumn{2}{|c|}{ First year } & \multicolumn{2}{|c|}{ Second vear } & \multirow{2}{*}{$\begin{array}{c}\text { No. of } \\
\text { absences }\end{array}$} & \multicolumn{2}{|c|}{ First year } & \multicolumn{2}{|c|}{ Second year } & \multirow{2}{*}{$\begin{array}{c}\text { No. of } \\
\text { absences }\end{array}$} & \multicolumn{2}{|c|}{ First vear } & \multicolumn{2}{|c|}{ Second year } \\
\hline & Obs. & Exp. & Obs. & Exp. & & Obs. & Exp. & Obs. & Exp. & & Obs. & Exp. & Obs. & Exp. \\
\hline $\begin{array}{l}0 \\
1 \\
2 \\
3 \\
4 \\
5 \\
6 \\
7+\end{array}$ & $\begin{array}{r}92 \\
79 \\
41 \\
26 \\
20 \\
9 \\
10 \\
-\end{array}$ & $\begin{array}{r}92 \cdot 1 \\
74 \cdot 6 \\
48 \cdot 0 \\
28 \cdot 2 \\
15 \cdot 8 \\
8 \cdot 6 \\
9 \cdot 5 \\
-\end{array}$ & $\begin{array}{r}82 \\
74 \\
53 \\
26 \\
14 \\
12 \\
7 \\
9\end{array}$ & $\begin{array}{r}83 \cdot 5 \\
71 \cdot 4 \\
48 \cdot 9 \\
30 \cdot 6 \\
18 \cdot 3 \\
10 \cdot 6 \\
6 \cdot 1 \\
7 \cdot 6\end{array}$ & $\begin{array}{l}0 \\
1 \\
2 \\
3 \\
4 \\
5 \\
6 \\
7+\end{array}$ & $\begin{array}{r}162 \\
104 \\
47 \\
26 \\
19 \\
9 \\
6 \\
7\end{array}$ & $\begin{array}{r}163 \cdot 5 \\
96 \cdot 1 \\
54 \cdot 1 \\
30 \cdot 0 \\
16 \cdot 5 \\
9 \cdot 0 \\
4.9 \\
5.9\end{array}$ & $\begin{array}{r}109 \\
115 \\
72 \\
36 \\
13 \\
15 \\
10 \\
10\end{array}$ & $\begin{array}{r}115 \cdot 4 \\
101 \cdot 9 \\
68 \cdot 9 \\
41 \cdot 8 \\
23 \cdot 9 \\
13 \cdot 2 \\
7 \cdot 1 \\
7 \cdot 8\end{array}$ & $\begin{array}{l}0 \\
1 \\
2 \\
3 \\
4 \\
5 \\
6 \\
7 \\
8+\end{array}$ & $\begin{array}{l}23 \\
32 \\
72 \\
86 \\
68 \\
49 \\
20 \\
14 \\
16\end{array}$ & $\begin{array}{l}14 \cdot 6 \\
45 \cdot 4 \\
72 \cdot 8 \\
79 \cdot 9 \\
67 \cdot 5 \\
46 \cdot 7 \\
27 \cdot 6 \\
14 \cdot 4 \\
11 \cdot 2\end{array}$ & $\begin{array}{l}16 \\
32 \\
55 \\
93 \\
82 \\
50 \\
22 \\
14 \\
16\end{array}$ & $\begin{array}{l}10 \cdot 8 \\
38 \cdot 4 \\
68 \cdot 2 \\
80 \cdot 9 \\
722 \\
51 \cdot 6 \\
30 \cdot 8 \\
15 \cdot 8 \\
11 \cdot 4\end{array}$ \\
\hline $\begin{array}{l}\text { n } \\
\text { Mean } \\
\text { Variance } \\
k \\
\text { SE of k } \\
\chi^{2} \\
\text { df } \\
\text { P }\end{array}$ & \multicolumn{2}{|c|}{$\begin{array}{c}277 \\
1.549 \\
2.850 \\
1.700 \\
0.348 \\
2.61 \\
4 \\
0.50-0.75\end{array}$} & \multicolumn{2}{|c|}{$\begin{array}{c}277 \\
1 \cdot 754 \\
3.584 \\
1.670 \\
0.311 \\
2.77 \\
5 \\
0.50-0.75\end{array}$} & $\begin{array}{l}n \\
\text { Mean } \\
\text { Variance } \\
k \\
\text { SE of } k \\
\chi^{2} \\
\text { df } \\
P\end{array}$ & \multicolumn{2}{|c|}{$\begin{array}{c}380 \\
1.271 \\
2.678 \\
1.093 \\
0.176 \\
2.94 \\
5 \\
0.50-0.75\end{array}$} & \multicolumn{2}{|c|}{$\begin{array}{c}380 \\
1.663 \\
3.242 \\
1.881 \\
0.318 \\
10.06 \\
5 \\
0.05-0.10\end{array}$} & $\begin{array}{l}n \\
\text { Mean } \\
\text { Variance } \\
k \\
\text { SE of } k \\
\chi^{2} \\
\text { df } \\
P\end{array}$ & \multicolumn{2}{|c|}{$\begin{array}{c}380 \\
3 \cdot 413 \\
3 \cdot 721 \\
36 \cdot 500 \\
32 \cdot 230 \\
13 \cdot 65 \\
6 \\
0.05-0.025\end{array}$} & \multicolumn{2}{|c|}{$\begin{array}{c}380 \\
3.571 \\
3.449 \\
537 \cdot 200 \\
56 \cdot 743 \\
13 \cdot 82 \\
6 \\
0.05-0.025\end{array}$} \\
\hline
\end{tabular}

Terminal frequencies pooled for $\chi^{2}$ calculation

telegraphists was moderately high. This type of absence was correlated with certified absence over the full two-and-a-half-year period in both Sydney telegraphists $(\mathrm{r}=0.40, \mathrm{P}<0.001)$ (Fig. 5) and mail sorters $(\mathrm{r}=0.52, \mathrm{P}<0.001)$.

\section{Associated absence}

Among Sydney telegraphists each type of repeater was more common in employees whose absence was attributed to neurosis than in others (Fig. 6). Similarly, $72 \%$ of repeaters and $25 \%$ of nonrepeaters had at least one recorded absence bearing a diagnosis of an alimentary disorder, the corresponding proportions for upper respiratory absence

T A B L E 6

Numbers of Certified Absences attributed to INFLUENZA (INCLUDING 'FLU' BUT NOT 'GASTRIC FlU') in Successive Years in Two Occupational GROUPS IN SYDNEY

\begin{tabular}{|c|c|c|}
\hline \multirow{2}{*}{ Occupation } & \multicolumn{2}{|c|}{$\begin{array}{c}\text { Absences certified due } \\
\text { to influenza }\end{array}$} \\
\hline & $\begin{array}{l}\text { First } \\
\text { year }\end{array}$ & $\begin{array}{l}\text { Second } \\
\text { year }\end{array}$ \\
\hline $\begin{array}{l}\text { Telegraphists (297) } \\
\text { Mail sorters (380) }\end{array}$ & $\begin{array}{l}64 \\
49\end{array}$ & $\begin{array}{l}116 \\
147\end{array}$ \\
\hline
\end{tabular}

being 88 and $54 \%$. In each occupational group the employee whose absence was attributed to injury was more than twice as likely as the employee in the whole group to have been a repeater (Fig. 7).

\section{Associations with interview data}

The repeater was found to differ from the employee who was rarely absent in respect of a number of attributes noted at interview (Table 9). Only the proportions of drinkers and of those dissatisfied with pay differed significantly. Restriction of the comparison to Sydney telegraphists because of the many variations between occupational and geographic groups limited the numbers, and thus probable real differences did not attain significance.

The attributes listed are, of course, interrelated in various ways. For example, in the analysis of interview data (Ferguson, 1969) moderate to heavy drinking was associated with neurosis, peptic ulcer, the single state (never married, separated, divorced or widowed), double jobbing, smoking, and dissatisfaction with job and with pay, among other attributes. (A moderate drinker was one who admitted that he drank regularly, usually every day, in moderate quantities, for example up to 2 litres of beer after work with perhaps some at lunch or after dinner or at clubs at the weekend; he said he was rarely or never grossly intoxicated and did not admit to losing time from work as a result. A heavy drinker exceeded these criteria; his drinking had 
T A B L E 7

Parameters (Arithmetic Mean and Positive Exponent k) of Negative Binomial Distributions of Sickness Absence in Successive Years in Two Occupational Groups in Sydney

\begin{tabular}{|c|c|c|c|c|c|c|}
\hline \multirow{2}{*}{ Occupation and absenco type } & \multicolumn{3}{|c|}{ First year } & \multicolumn{3}{|c|}{ Second year } \\
\hline & Mean & k & S.E. of $\mathrm{K}$ & Mean & k & S.E. of $\mathrm{k}$ \\
\hline $\begin{array}{l}277 \text { telegraphists } \\
\text { Certified absence }\end{array}$ & $1 \cdot 549$ & $\begin{array}{ll}\text { k1 } & 1.843 \\
\text { k2 } & 1.707 \\
\text { k3 } & 1.700\end{array}$ & $\begin{array}{l}0.426 \\
0.387 \\
0.347\end{array}$ & $1 \cdot 754$ & $\begin{array}{lc}\text { k1 } & 1.682 \\
\text { k2 } & 1.761 \\
\text { k3 } & 1.670\end{array}$ & $\begin{array}{l}0 \cdot 354 \\
0 \cdot 383 \\
0 \cdot 311\end{array}$ \\
\hline $\begin{array}{l}380 \text { mail sorters } \\
\text { Certified absence }\end{array}$ & $1 \cdot 271$ & $\begin{array}{ll}\text { k1 } & 1 \cdot 148 \\
\text { k2 } & 1 \cdot 134 \\
\text { k3 } & 1 \cdot 093\end{array}$ & $\begin{array}{l}0 \cdot 217 \\
0 \cdot 198 \\
0 \cdot 176\end{array}$ & $1 \cdot 663$ & $\begin{array}{ll}\text { k1 } & 1 \cdot 751 \\
\text { k2 } & 2 \cdot 278 \\
\text { k3 } & 1 \cdot 881\end{array}$ & $\begin{array}{l}0 \cdot 327 \\
0 \cdot 502 \\
0 \cdot 318\end{array}$ \\
\hline $\begin{array}{l}380 \text { mail sorters } \\
\text { Uncertified absence }\end{array}$ & $3 \cdot 413$ & $\begin{array}{lr}\text { k1 } & 37 \cdot 883 \\
\text { k2 } & 7 \cdot 369 \\
\text { k3 } & 36 \cdot 500\end{array}$ & $\begin{array}{r}33 \cdot 689 \\
2 \cdot 908 \\
32 \cdot 230\end{array}$ & $3 \cdot 571$ & $\begin{array}{lr}\text { k1 } & 104 \cdot 281 \\
\text { k2 } & 13 \cdot 469 \\
\text { k3 } & 537 \cdot 199\end{array}$ & $\begin{array}{r}12 \cdot 331 \\
8 \cdot 942 \\
56 \cdot 743\end{array}$ \\
\hline
\end{tabular}

$k 1$ is based on first and second moments, $k 2$ on the ratio of the total number of employees in the sample to the number without episodes, $\mathrm{k} 3$ on the method of maximum likelihood (Bliss and Fisher, 1953).

T A B L E 8

ObServed Product-Moment Correlation CoEFFICIENTS (r) AND EXPECTED CORRELATION CoEFFICIENTS DERIVED FROM PARAMETERS OF UNIVARIATE Negative Binomial $(\rho)$ Between Numbers of Certified AbSences of Each Individual in Two SUCCESSIVE YeARS, TOGETHER WITH $r$ FOR UNCERTIfied AbSENCE, IN Two Occupational Groups in SYDNEY

\begin{tabular}{|c|c|c|c|}
\hline \multirow{2}{*}{ Occupation } & \multicolumn{2}{|c|}{$\begin{array}{l}\text { Certified } \\
\text { absence }\end{array}$} & \multirow{2}{*}{$\begin{array}{c}\begin{array}{c}\text { Uncertified } \\
\text { absence }\end{array} \\
\mathrm{r}\end{array}$} \\
\hline & $\mathbf{r}$ & $\rho$ & \\
\hline $\begin{array}{l}\text { Telegraphist (277) } \\
\text { Mail sorter (380) }\end{array}$ & $\begin{array}{l}0.561 \\
0.499\end{array}$ & $\begin{array}{l}0.476 \\
0.537\end{array}$ & $\begin{array}{l}0.703 \\
0.481\end{array}$ \\
\hline
\end{tabular}

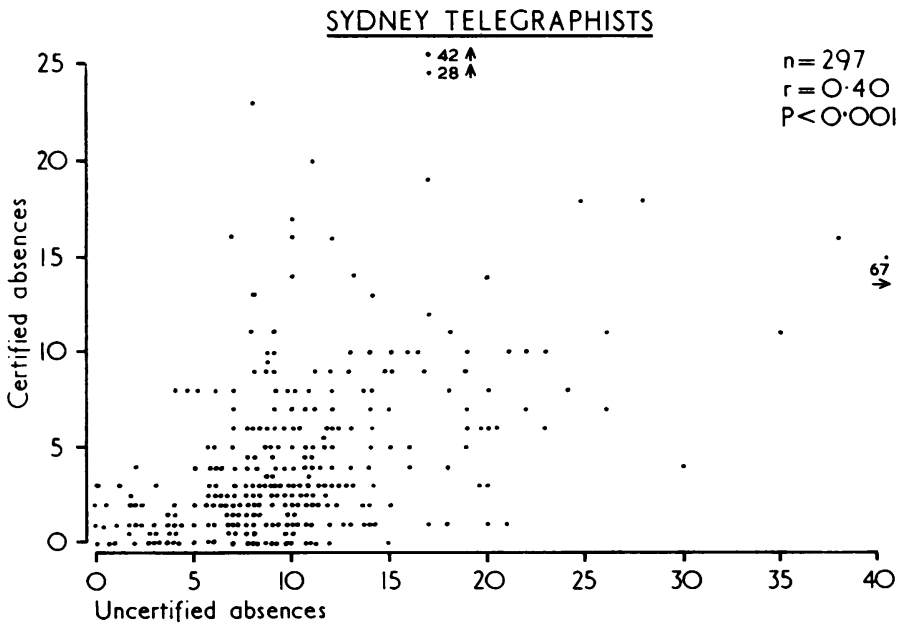

constituted a domestic, social or industrial problem.) A limited hierarchical sort of the findings compared in Table 9 revealed that in employees rarely absent but not in repeaters drinking was associated with dissatisfaction with pay $\left(\chi^{2}=6.81, \mathrm{P}<0.01\right)$ and with rural upbringing $\left(\chi^{2}=4.94, P<0.05\right)$, and in both groups with avoidance of overtime $\left(\chi^{2}=7 \cdot 13\right.$, $\mathbf{P}<0.01)$. Dissatisfaction with pay was also associated with double jobbing $\left(\chi^{2}=10 \cdot 08, \mathrm{P}<\right.$ 0.002).

In the cases of a far larger number of attributes little difference was found; out of over 90 tested, these attributes included, for example, age, deprivation of one or both parents before the age of 11 years, security, adverse attitudes to job, supervision, and to the work environment, asthma, bronchitis, ulcer, dyspepsia, tension headache, obesity, and

5. Product-moment correlation between numbers of certified and uncertified absences in individual Sydney telegraphists over two-and-a-half-year period. 


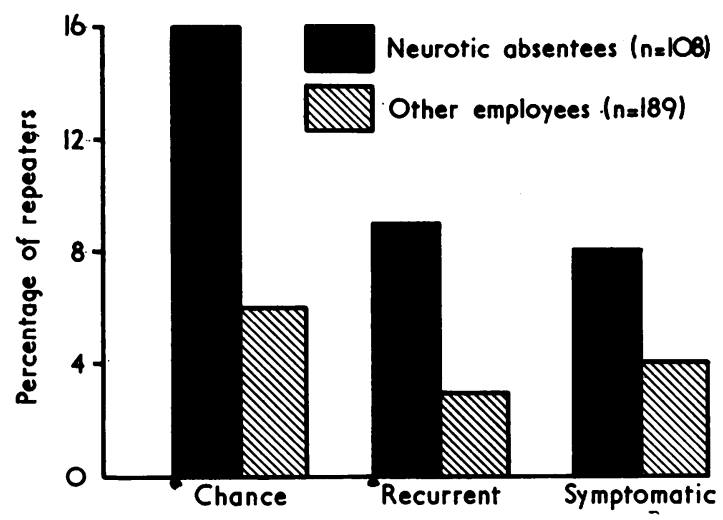

FIG. 6. Comparison of Sydney telegraphists with absence attributed to neurosis and those without in respect of occurrence of each type of repeater. The total proportion of repeaters in neurotic absentees was $33 \%$ and in other Sydney telegraphists $13 \%$.

travel time to work exceeding one hour. Admission, at interview, of seeking unjustified certified absence was commoner in moderate to heavy drinkers $\left(\chi^{2}=15.72, P<0.001\right)$ and in those who had second jobs $\left(\chi^{2}=10 \cdot 14, P<0.002\right)$, but less common in neurotics $\left(\chi^{2}=3 \cdot 12, \mathrm{P}<0.05\right)$. The self-admitted unjustified absentee appeared to obtain certificates not so much because of discontent or ill health (except that due to drinking) as for practical need or convenience. The neurotic employee was more likely than others to have frequent absence but less likely to transgress in obtaining it.

About one quarter of repeaters had little or no evidence of chronic or recurrent ill health at interview, and, conversely, the same proportion of employees who were rarely absent had much such evidence $\left(\chi^{2}=3.36, \mathrm{P}<0.05\right)$ (Fig. 8).

\section{Discussion}

In the occupational groups investigated, certain
T A B L E 9

Comparison of Personal, Industrial, and Social AtTributes of Repeaters and the Rarely AbSENT AMONG SYDNEY TELEGRAPHISTS

\begin{tabular}{|c|c|c|c|}
\hline \multirow{2}{*}{ Attributes noted at interview } & \multicolumn{2}{|c|}{ Certified absences $(\%)$} & \multirow[b]{2}{*}{$x^{2}$} \\
\hline & $\begin{array}{c}0-1 \\
(n=61)\end{array}$ & $\begin{array}{c}8+ \\
(n=48)\end{array}$ & \\
\hline 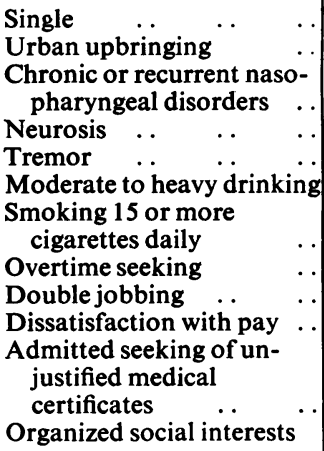 & $\begin{array}{l}31 \\
36 \\
\\
23 \\
41 \\
32 \\
57\end{array}$ & $\begin{array}{l}19 \\
54 \\
\\
35 \\
52 \\
50 \\
81\end{array}$ & $\begin{array}{l}2 \cdot 12 \\
2 \cdot 87 \\
\\
1.49 \\
0.93 \\
2 \cdot 62 \\
5.96^{1}\end{array}$ \\
\hline
\end{tabular}

${ }^{1 P}<0.02$

${ }^{2} \mathrm{P}<0.01$

conclusions may be made from this study of sickness absence repeaters: the observed frequency of certified sickness absence can be consistently fitted by the negative binomial distribution, which has been considered to support the concept of proneness to such absence; the degree and nature of repeating varies geographically and occupationally, apparently in response to multiple personal, social, and job factors; absence attributed to neurosis, alimentary and respiratory disorder, and injury is relatively common in repeaters; except for an adverse attitude to remuneration and a history of drinking, expected associations of repeating with social and personal attributes determined at interview are poorly realized; and the state of health suggested by sickness

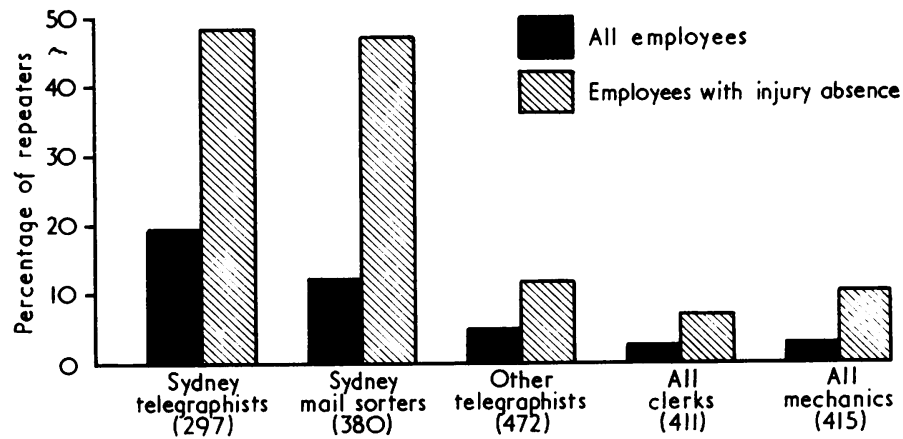

FIG. 7. Absence attributed to injury in relation to absence in five occupational groupings. 


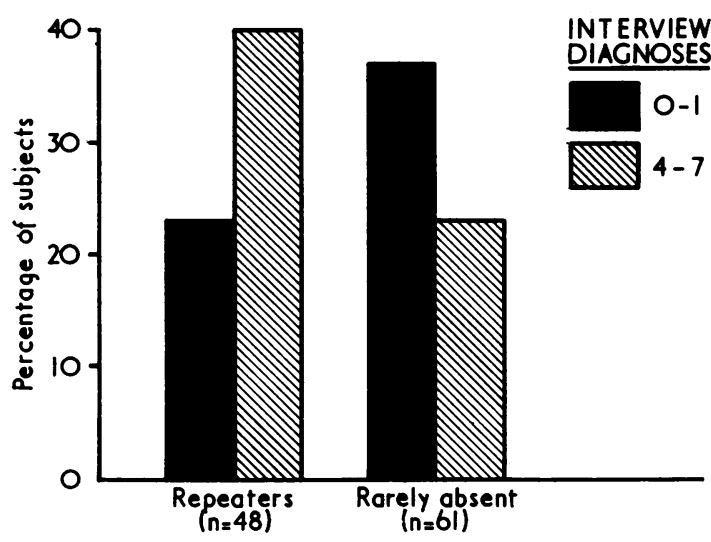

FIG. 8. Comparison of repeaters with rarely absent employees in respect of proportions having few and many diagnoses of chronic or recurrent ill health made at interview, in Sydney telegraphists.

absence diagnoses often bears little relation to state of health revealed by medical interview.

The observed distribution of frequency of certified absence among groups which differed widely in occupation and in nature and amount of absence fitted the same theoretical distribution more or less closely, though the varied form of the curve suggested different patterns of liability in the various groups (Glasser, 1970). The interpretation, other than that of proneness, which can be put upon the fitting of the distribution to biological data has already been referred to. The groups considered in the present paper should have been relatively homogeneous in being permanent employees whose turnover was low and who should have been evenly exposed to a degree of risk which should have remained fairly constant in time or have changed equally for all. This homogeneity should enhance the interpretation of proneness from the negative binomial, because a fit in the face of heterogeneity would suggest the operation of confounding phenomena explored by Froggatt (1970b). That the observed two-and-a-half-year frequency in telegraphists, which should have been the most homogeneous of the groups studied, departed significantly from the negative binomial might indicate confounding: some heterogeneity is inevitable in any group; sick leave was openly manipulated by some telegraphists, who were known to have a panel of medical practitioners to whom they could turn for certificates; inefficient estimators of the parameters of the distribution may have caused unwarranted rejection of the model (Sichel, 1951); and a major change in the equipment, involving semi-automation, was introduced during the two-and-a-half-year period, to which attitudes were divided. Exposure to risk of influenza may or may not have been uniform. Within each year the observed certified absence frequencies in telegraphists did follow the negative binomial closely, and the parameters for the two separate years were stable, evidence in support of the proneness interpretation.

The Poisson distribution, with its implication of equal chance of absence, certainly did not fit the data but other distributions, for example the Neyman type A or 'Short' ('spells' hypothesis), or the Hermite (the 'cluster' hypothesis) were not applied, though found to fit the short-term absence data of Froggatt (1970b) in some cases. 'Contagion', the influence of one absence on the likelihood of another, cannot be eliminated as an explanation of the negative binomial fit on the evidence of the univariate analysis alone.

The symmetrical bivariate model may have been appropriate for certified absence, even if, partly due to influenza, means differed in the mail sorters, but neither the univariate nor bivariate approach fully explained the observations on uncertified absence. If proneness applied, it was confounded by other influences.

The interyear correlations gave support to the proneness interpretation as also did the concordance of the correlation coefficient based on observed frequencies in the two years with that calculated from the univariate parameters of the first year. In one case the latter exceeded the former and in the other was less than it, contrary to the experience of Arbous and Sichel (1954) and Glasser (1970) that life does not live up to expectations. A two-year period may not have been enough to reveal the dilution of time in the face of an assumed constant personal liability.

The exceptional occurrence of repeating in Sydney telegraphists was only one of a number of indications including job dissatisfaction, drinking habits, and prevalence of neurosis (Ferguson, 1969), which might be regarded as evidence of adverse organizational factors in the work of this group. Monotony with overload without responsible autonomy in a large group (Revans, 1960) and poor opportunity may induce absence through lack of job satisfaction. If this were so, it was not reflected in any association between repeating and adverse attitudes to job, supervision or work environment. Indeed, there was evidence from the present study that the repeater, particularly the symptomatic repeater, was often not so frequently absent through discontent or ill health as for convenience.

Was repeated absence associated with indulgence in alcohol symptomatic of industrial malaise or organizational fault rather than of the effects of the drinking and the drinker's personality? Repeaters were more often drinkers than were the rarely absent, as noted also by Trice (1965) and Pell and D'Alonzo (1970) in identified alcoholics, but 
though drinking was associated strongly with job dissatisfaction, repeating was not, at least in the Sydney telegraphists. Neurosis, smoking, and peptic ulcer, found to be linked with drinking: and the physical consequences of drinking to excess no doubt contributed to the liability of the drinker to be absent repeatedly. The personality of the heavy drinker and the behavioural changes induced by drinking probably also increased the liability, although 15 out of 47 heavy drinkers $(32 \%)$ in this study over two and a half years, and $38 \%$ of Pell and D'Alonzo's identified alcoholics over one year, had no certified absence. However, a number of employees interviewed claimed that their excessive drinking arose out of working short (61 hours) shifts at any hour and out of broken shifts when the only thing to do in the two-hour interval was to drink. Trice (1965) identified a drinking 'climate' in certain classes of workers, where there was an opportunity to drink and an acceptance of heavy drinking behaviour. These were manual workers of low status, although employees in higher positions may have more desire and opportunity to hide their habit. Some of the industrial situations regarded by Roman and Trice (1970) as occupational 'risk factors' applied in the case of telegraphists, including flexibility of schedules and occupational obsolescence. Certainly there was an acceptance of heavy drinking behaviour in the group.

Repeaters tended to be neurotic, as suggested by the findings of Hinkle et al. (1961), Trice (1965), and Howell and Crown (1971), but the association was weak. A much stronger tendency to absence attributed to neurosis was found in repeaters, as was also noted by Taylor (1968a), but such absence in the present study did not necessarily mean that the person was clinically assessable as neurotic at interview (Ferguson, 1969). Though having a second job was not associated strongly with repeating, again as noted by Taylor some symptomatic repeaters were stable double jobbers, while some who were rarely absent approached the irresponsible selfseeker of Hinkle et al. (1961). Working overtime tended to be linked negatively with repeating, as noted by Walker and de la Mare (1971). Repeaters were a mixed bag and not homogeneous. Perhaps the most striking observation about the many comparisons made of repeaters and the rarely absent in this study was the lack of major differences in personal and social attributes.

The characterization of repeater type by diagnostic pattern of certificates did not prove to be particularly helpful. Separation into types is imprecise, and moreover probably artificial, possibly revealing different certifying habits as much as different types of absence behaviour. Were the separation a true indication of absence behaviour, the occurrence of recurrent repeaters should have been similar in each city, wide interstate variations in chronic or recurrent disease prevalence being unlikely.

Social factors contributed to the number of repeaters in Sydney. Conjugal failure, drinking, smoking, drugtaking, and other evidence of personal maladjustment were more evident in the employees in Sydney than in their Melbourne or Brisbane colleagues, but Sydney generally has a poorer record in these respects (Ferguson, 1969); heavy drinking was found to be normative behaviour for adult males in Sydney by Encel and Kotowicz (1970).

If the evidence of this study is any guide, there was more ready acceptance by workers, management, and the medical profession in Sydney than in Melbourne or Brisbane of seeking and justification of medically 'unjustified' absence. It is well recognized that an illness factor is not necessarily present in certified absence, though the taking of unjustified absence could in itself be regarded as evidence of disease.

Some repeaters had little chronic disease, some rarely absent employees had much. To an extent this finding only exemplifies the poor relation between the results of incidence (acute absence mostly) and prevalence (chronic ill health) studies generally; different things are being measured. Semmence (1971) considered physical examination or other cross-sectional procedure at one time a poor predictor of absence. However, these observations by no means entirely explain the absence resistance of many rarely absent employees despite much ill health (Taylor, 1968a and b).

The past record seems to be the best predictor of absence, whether certified absence (Hinkle et al., 1961; Taylor, 1968a) or absenteeism (Glasser, 1970), of consultation in general practice (Froggatt et al., 1969), and of neurosis (Fraser, 1947). However, the predictability of a person's liability to absence from his past record may be to some extent only of academic interest, as suggested by Froggatt (1970b), because the absence pattern is likely to remain consistent. The ability to predict absence with a measureable degree of certainty (Arbous and Sichel, 1954) does not seem to have been used as a basis for management action. Yet the repeater should be identified for what assistance can be given him, if he needs it. An effective preventive occupational health service is indispensible in the management of such cases, and it is usually assumed that the service can do much to reduce absenteeism, though assessment of benefits of services is difficult. In view of the lack, to date, of knowledge of any one strong causative factor in repeating, as distinct from the many weakly associated factors demonstrated, it would seem more profitable to attack those features in job design, or ganization, and management which appear to influence motivation to come to work. This approach is aimed at all employees, not only the 
repeater; repeating is only the arbitrary upper end of a continuum. It is much more difficult to control social factors implicit in the geographic differences noted in this study.

The author is indebted to the Computer Section of the Commonwealth Scientific and Industrial Research Organization at the University of Sydney for the calculations of negative binomial and Poisson distributions, to Mr. C. Gray, statistician in the Organization, for advice and assistance, and to the many persons in the undertaking studied who co-operated in one way or another. The work was carried out under the general direction of Dr. G. C. Smith, Head of the Occupational Health Section in the School of Public Health and Tropical Medicine, University of Sydney.

\section{References}

Acheson, E. D. (1968). In: Procaedings of Symposium on Absence from Work Attributed to Sickness, London 1968, edited by A. Ward Gardner, pp. 103-105. Society of Occupational Medicine, London.

Arbous, A. G., and Sichel, H. S. (1954). New techniques for the analysis of absenteeism data. Biometrika, 41, 77-90.

Bashford, H. (1942). Supervision of sick absence in industry. Lancet, 2, 289-290.

Bliss, C. I., and Fisher, R. A. (1953). Fitting the negative binomial distribution to biological data. Biometrics, 9, 176-200.

Blumberg, M. S., and Coffin, J. C. (1956). Syllabus on work absence. Arch. industr. Hlth, 13, 55-70.

Chiesman, W. E. (1957). Clinical aspects of absenteeism. Roy. Soc. Prom. Hlth (N.Z.) J., 77, 681-686.

Encel, S., and Kotowicz, K. (1970). Heavy drinking and alcoholism. Med. J. Aust., 1, 607-612.

Farmer, E., and Chambers, E. G. (1926). A psychological study of individual differences in accident rates. M.R.C. industr. Fat. Res. Bd. Rep., No. 38, H.M.S.O., London.

Ferguson, D. A. (1969). Stress and health in telegraphy. M.D. thesis, University of Sydney.

- (1971). An Australian study of telegraphists' cramp. Brit. J. industr. Med., 28, 280-285.

Fortuin, G. J. (1955). Sickness absenteeism. Bull. Wld Hlth Org., 13, 513-541.

Fraser, R. (1947). The incidence of neurosis among factory workers. M.R.C. industr. Hlth Res. Bd. No. 90, H.M.S.O. London.

Froggatt, P. (1970a). Short-term absence from industry. II. Temporal variation and inter-association with other recorded factors. Brit. J. industr. Med., 27, 211-224.

- (1970b). Short-term absence from industry. III. The inference of 'proneness' and a search for causes. Brit. J. industr. Med., 27, 297-312.

-, Dudgeon, M. Y., and Merrett, J. D. (1969). Consultations in general practice - analysis of individual frequencies. Brit. J. prev. soc. Med., 23, 1-11.

- and Smiley, J. A. (1964). The concept of accident proneness: a review. Brit. J. industr. Med., 21, 1-12.

Gafafer, W. M. (Editor) (1943). Absenteeism. In: Manual of Industrial Hygiene, pp. 420-466. W. B. Saunders, Philadelphia.

Glasser, J. H. (1970). A stochastic model for industrial illness absenteeism. Amer. J. pub. Hlth, 60, 1936-1944.

Greenwood, M., and Woods, H. M. (1919). The incidence of industrial accidents upon individuals with special refer- ence to multiple accidents. Industr. Fatigue Res. Bd. Rep. No. 4, H.M.S.O., London.

— and Yule, G. U. (1920). An inquiry into the nature of frequency distributions representative of multiple happenings with particular reference to the occurrence of multiple attacks of disease or of repeated accidents. J. roy. stat. Soc., 83, 255-279.

Hinkle, L. E., Pinsky, R. H., Bross, I. D. J., and Plummer, N. (1956). The distribution of sickness disability in a homogeneous group of 'healthy adult men'. Amer. J. Hyg., 64, 220-242.

- Plummer, N., and Whitney, L. H. (1961). The continuity of patterns of illness and the prediction of future health. J. occup. Med., 3, 417-423.

Howell, R. W., and Crown, S. (1971). Sickness absence levels and personality inventory scores. Brit. J. industr. Med., 28, 126-130.

Kemp, R. (1963). The familiar face. Lancet, 1, 1223-1226.

Lokander, S. (1962). Sick absence in a Swedish company. A socio-medical study. Acta med. scand., Suppl. 377, p. 70.

London Transport Executive (1956). Health in Industry. $A$ Contribution to the Study of Sickness Absence. Butterworth, London.

Pell, S., and D'Alonzo, C. A. (1970). Sickness absenteeism of alcoholics. J. occup. Med., 12, 198-210.

Plummer, N., and Hinkle, L. E. (1955). Sickness absenteeism. Arch. industr. Hlth, 11, 218-230.

Revans, R. W. (1960). Morale and the size of the working group. In: Modern Trends in Occupational Health, edited by R. S. F. Schillıng, pp. 196-208. Butterworth, London.

Roman, P. M., and Trice, H. M. (1970). The development of deviant drinking behaviour. Arch. environm. Hlth, 20, 424-435.

Russell, W. T., Whitwell, G. P. B., and Ryle, J. A. (1947). Studies in occupational morbidity (1). Brit. J. industr. Med., 4, 56-61.

Schilling, R. S. F. (1960). The measurement of health. In: Modern Trends in Occupational Health, edited by R. S. F. Schilling, pp. 1-19. Butterworth, London.

Semmence, A. (1971). Rising sickness absence in Great Britain - a general practitioner's view. J. roy. Coll. gen. Practit., 21, 125-146.

Shepherd, R. D., and Walker, J. (1958). Absence from work in relation to wage level and family responsibility. Brit. $J$. industr. Med., 15, 52-61.

Sichel, H. S. (1951). The estimation of the parameters of a negative binomial distribution with special reference to psychological data. Psychometrika, 16, 107-127.

Smith, D. J. (1970). Absenteeism and 'presenteeism' in industry. Arch. environm. Hlth, 21, 670-677.

Sutherland, I., and Whitwell, G. P. B. (1948). Studies in occupational morbidity (2). Brit. J. industr. Med., 5, 77-87.

Taylor, P. J. (1967). Individual variations in sickness absence. Brit. J. industr. Med., 24, 169-177.

- (1968a). Personal factors associated with sickness absence. Brit. J. industr. Med., 25, 106-118.

- (1968b). Sickness absence resistance. Trans. Soc. occup. Med., 18, 96-100.

Trice, H. M. (1965). Alcoholic employees: a comparison of psychotic, neurotic, and 'normal' personnel. J. occup. Med., 7, 94-99.

Walker, J., and de la Mare, G. (1971). Absence from work in relation to length and distribution of shift hours. Brit. $J$. industr. Med., 28, 36-44.

World Health Organization (1957). International Classification of Diseases. W.H.O., Geneva.

Received for publication September 18, 1971. 